\title{
Inhibition of the Renin Angiotensin System during Autologous Stem Cell Transplant Does Not Impact Time to Engraftment
}

\author{
Anita J. Kumar ${ }^{1}$, Joseph Carver $^{1,2}$, Noelle V. Frey ${ }^{1}$ \\ ${ }^{1}$ Abramson Cancer Center, University of Pennsylvania, Philadelphia, USA; ${ }^{2}$ Division of Cardiovascular Medicine, University of \\ Pennsylvania, Philadelphia, USA. \\ Email: Anita.kumar@uphs.upenn.edu
}

Received September $9^{\text {th }}, 2012$; revised October $11^{\text {th }}, 2012$; accepted October $21^{\text {st }}, 2012$

\begin{abstract}
Background: The renin angiotensin system RAS modulates hematopoiesis via local effects in the bone marrow. Angiotensin converting enzyme inhibitors (ACEi) and angiotensin receptor blockers (ARBs) may adversely impact hematopoiesis and time to engraftment in patients undergoing stem cell transplant (SCT). Our study assesses whether the use of ACEi or ARBs delays time to engraftment in patients with multiple myeloma undergoing a melphalan based autologous SCT. Methods: A retrospective review of 58 patients who underwent autologous SCT with a melphalan 200 $\mathrm{mg} / \mathrm{m}^{2}$ conditioning regimen for multiple myeloma between January 1 and December 31, 2010 was performed. Results: Of 58 evaluable patients, 47 underwent autologous SCT without an ACEi or ARB (control group), and 11 patients were given ACEi or ARBs (treatment group). Mean time to neutrophil engraftment was 11.5 days in the control group, and 11.3 days in treatment group $(\mathrm{p}=0.60)$. Mean time to platelet engraftment in control group was 13.5 days and 15.1 days in treatment group $(p=0.2)$. There was no statistically significant difference between groups in time to neutropenic fever and length of hospital stay. Conclusion: Our study demonstrates no significant difference in time to engraftment, incidence of neutropenic fever, or length of hospital stay between patients receiving ACEi or ARBS compared to control subjects. We demonstrate that use of low to moderate dose ACEi or ARB does not lead to prolonged time to engraftment and is safe to use in patients undergoing autologous SCT for multiple myeloma.
\end{abstract}

Keywords: Multiple Myeloma; ACE Inhibitor; Angiotensin Receptor Blocker; Melphalan; Neutropenia

\section{Introduction}

Angiotensin converting enzyme inhibitors (ACEi) and angiotensin receptor blockers (ARBs), which modify the renin-angiotensin system (RAS), are widely used in the treatment of hypertension, heart failure and chronic kidney disease. ACE inhibitors suppress conversion of angiotensin I to angiotensin II, and ARBs block the interacttion of angiotensin II with the AT1 receptor, preventing activation of various cellular pathways. Recently, the RAS has been implicated in pathways beyond cardio vascular and renal regulation, including the modulation of hematopoiesis via local effects in the bone marrow [1].

Investigators have noted decreased hematocrit levels in patients taking ACE inhibitors and ARBs [2,3]. Further studies demonstrate that the RAS itself leads to increased endogenous erythropoietin production [4], and that ACE inhibitor use in hemodialysis patients results in decreased plasma erythropoietin level [5]. Mechanisms proposed to explain this finding include increased $\mathrm{N}$ acetyl-seryl-aspartyl-lysyl-proline (AcSDKP), and direct effects of angiotensin II $[6,7]$.

Dose-intensive chemotherapy followed by autologous SCT remains a mainstay of therapy for many patients with multiple myeloma (MM). Risks of transplant are related in part to complications of therapy related cytopenias. Given the role of the RAS in hematopoiesis, this study was designed to test the hypothesis that the use of ACEi and ARBs in patients undergoing transplant may delay time to both platelet and neutrophil engraftment, which may lead to increased transplant related morbidity. Although many studies have been completed to better understand the role of the RAS on hematopoiesis, no studies have been performed to assess the potential clinical impact of RAS inhibitors on engraftment after SCT. This study evaluates whether use of ACE inhibitors or ARBs affects engraftment immediately following autologous SCT for patients with MM. 


\section{Methods}

\subsection{Patient Population and Transplant Procedures}

This retrospective cohort study was approved by and conducted in accordance with the requirements of the institutional review board of the Hospital of the University of Pennsylvania. Subjects were identified through query of the hospital transplant database and eligibility confirmed and data collected through retrospective chart review. To be eligible, patients must have received an autologous SCT for multiple myeloma using melphalan at $200 \mathrm{mg} / \mathrm{m}^{2}$ as a conditioning regimen at the Hospital of the University of Pennsylvania between January 1, 2010 and December 31, 2010. Patients were excluded if they had undergone a prior autologous SCT. All patients underwent peripheral blood stem cell mobilization with granulocyte colony stimulating factor (G-CSF) either alone or after cytotoxic chemotherapy followed by peripheral blood stem cell collection via an apheresis procedure. Melphalan was administered at $200 \mathrm{mg} / \mathrm{m}^{2}$ on Day -2 of autologous stem cell infusion. Daily G-CSF was administered starting at Day +4 of SCT and continued until absolute neutrophil count (ANC) was greater than 1000 cells $/ \mu \mathrm{L}$ for at least two consecutive days. Prophylactic fluconazole and acyclovir were administered from Day -1 until Day +100 after SCT. ACEi/ ARB administration information was obtained by review of the inpatient medication administration records.

\subsection{Evaluation of Engraftment}

Neutrophil engraftment was defined as an ANC greater than or equal to 500 cells $/ \mu \mathrm{L}$ that persisted for at least three days. Platelet engraftment was defined as achieving platelets of at least 20,000 cells $/ \mu \mathrm{L}$ that persisted for at least three days. Time to engraftment was defined as number of days from Day 0 of SCT to the first day of platelet or neutrophil engraftment. Neutrophil and platelet engraftment were documented independently of platelet transfusions. Patients were excluded from engraftment analysis if platelets never dropped below 20,000 cells $/ \mu \mathrm{L}$. This exclusion parameter included patients who were transfused to goal platelets of $50,000 / \mu \mathrm{L}$ due to high bleeding risk, such as those receiving anti-coagulation.

\subsection{Statistical Analysis}

Patient characteristics (such as time to engraftment, presence of neutropenic fever, length of hospital stay) were collected and tested by analysis of variance (ANOVA) with experimental variable of $\mathrm{ACE} / \mathrm{ARB}$ treatment (ACE/ARB - receiving patients as the experimental group, patients who did not receive $\mathrm{ACE} / \mathrm{ARBs}$ as the control group). The threshold for statistical significance was a P-value of 0.05 .

\section{Results}

\subsection{Patient Characteristics}

58 patients who met eligibility criteria were identified. All patients received granulocyte colony stimulating factor of $5 \mathrm{mcg} / \mathrm{kg}$, rounded to either $300 \mathrm{mcg}$ or $480 \mathrm{mcg}$ from day +4 of transplant, until engraftment was achieved per institutional protocol. Of 58 evaluable patients, 47 patients (control group) underwent transplant without use of ACEi or ARB. Eleven patients (experimental group) continued their pre transplant maintenance ACEi or ARBs on day of stem cell reinfusion (Day 0) and throughout hospitalization. Reasons for ACEi/ARB use included hypertension and chronic kidney disease. Mean patient age was 59 years in control group, and 63 years in ACEi/ARB group. Median CD34 dose was $2.6 \times 10^{6}$ cells $/ \mathrm{kg}$ in ACEi/ARB group, and $2.5 \times 10^{6}$ cells $/ \mathrm{kg}$ in the control group (see Table 1(a)).

ACE inhibitors administered included lisinopril $(n=5)$, quinapril (1), benazapril (1) and enalapril (1). ARB treatment included valsartan (1), olmesartan (1) and valsar$\tan (1)$. These were administered in low to medium doses (See Table 1(b)).

Table 1. (a) Patient characteristics; (b) Dosing summary.

(a)

\begin{tabular}{ccc}
\hline & Control Group & ACE inhibitor/ARB \\
\hline Patients number (n) & 47 & 11 \\
Sex (\% Male) & 49 & 36 \\
Age (range), years & $59(44-75)$ & $63(53-70)$ \\
$\begin{array}{c}\text { CD34 dose } \\
\left(\times 10^{6} \text { cells } / \mathrm{kg}\right)\end{array}$ & $2.5(1.7-8.5)$ & $2.7(2.0-5.1)$ \\
\hline
\end{tabular}

(b)

\begin{tabular}{ccc}
\hline $\begin{array}{c}\text { Patients } \\
\text { number (n) }\end{array}$ & ACE inhibitor/ARB & Dose (mg/day) \\
\hline 1 & Lisinopril & 2.5 \\
2 & Lisinopril & 10 \\
2 & Lisinopril & 20 \\
2 & Valsartan & 160 \\
1 & Quinapril & 20 \\
1 & Benazapril & 20 \\
1 & Enalapril & 5 \\
\hline
\end{tabular}




\subsection{Engraftment}

Mean time to neutrophil engraftment was 11.5 days in the control group (range $10-16$ ) and 11.3 days in experimental group (range 10 - 13). There was no statistically significant difference in mean time to engraftment between groups $(t=0.52, p=0.60)$. A total of 10 patients ( 8 from the control group, and 2 from the experimental group) were excluded from platelet engraftment analysis, as they never dropped platelets below $20,000 / \mu \mathrm{L}$ due to a higher platelet goal for co-morbid conditions. In the control group, mean time to platelet engraftment occurred at 13.5 days (range 10 - 22). In the experimental group, mean time to platelet engraftment occurred at 15.1 days (11 - 25). These findings were not statistically significant $(\mathrm{t}=1.29, \mathrm{p}=0.2)$. There was no difference in red blood cell transfusion requirement (see Table 2).

\subsection{Hospital Course}

Neutropenic fever occurred after a mean length of stay of 6.3 days in the control group (range $0-11$ ). In the experimental group, mean time of neutropenic fever onset was 7.0 days (range 3 - 9). This difference was not statistically significant $(\mathrm{t}=0.94, \mathrm{p}=0.35)$. Mean length of hospital stay was 16.8 days in the control group (range 13 - 32). Mean length of hospital stay in experimental group was 19.2 days (range 15 - 32). This difference was not statistically significant $(\mathrm{t}=1.84, \mathrm{p}=0.07$, see Table 2).

Table 2. Patient outcomes.

\begin{tabular}{|c|c|c|c|c|}
\hline & $\begin{array}{l}\text { Mean } \\
\text { (days) }\end{array}$ & $\begin{array}{l}\text { Range } \\
\text { (days) }\end{array}$ & $\begin{array}{l}\text { Std. } \\
\text { Dev }\end{array}$ & $\begin{array}{c}\text { P-value } \\
\text { (t-test) }\end{array}$ \\
\hline \multicolumn{5}{|c|}{$\begin{array}{c}\text { Neutrophil } \\
\text { engraftment } \\
(\mathrm{ANC}>500 / \mu \mathrm{L})\end{array}$} \\
\hline Control & 11.5 & $10-16$ & 1.0 & \\
\hline $\mathrm{ACEi} / \mathrm{ARB}$ & 11.3 & $10-13$ & 0.9 & 0.60 \\
\hline \multicolumn{5}{|l|}{$\begin{array}{c}\text { Platelet } \\
\text { engraftment } \\
(>\mathbf{2 0 , 0 0 0} / \boldsymbol{\mu L})\end{array}$} \\
\hline Control & 13.5 & $10-22$ & 3.1 & \\
\hline $\mathrm{ACEi} / \mathrm{ARB}$ & 15.1 & $11-25$ & 4.4 & 0.20 \\
\hline \multicolumn{5}{|c|}{$\begin{array}{c}\text { Time to first } \\
\text { neutropenic fever }\end{array}$} \\
\hline Control & 6.3 & $0-11$ & 2.5 & \\
\hline ACEi/ARB & 7.0 & $3-9$ & 1.9 & 0.35 \\
\hline \multicolumn{5}{|l|}{$\begin{array}{c}\text { Length of } \\
\text { hospital stay }\end{array}$} \\
\hline Control & 16.8 & $13-32$ & 3.6 & \\
\hline ACEi/ARB & 19.2 & $15-32$ & 4.9 & 0.07 \\
\hline
\end{tabular}

\section{Discussion}

There are several putative mechanisms underlying the effects of the RAS on hematopoiesis at the level of the bone marrow, which involve concurrent roles for AcSDKP and angiotensin II. AcSDKP inhibits proliferation of hematopoietic pluripotent stem cells and blocks response of hematopoietic cells to proliferative stimuli in vitro [8]. However, AcSDKP is likely not the sole effecttor of the RAS on hematopoiesis, as animal models demonstrate that infusions of angiotensin II can correct anemia in ACE-deficient mice [9]. Angiotensin II also upregulates erythropoietin levels and affects mitosis of erythroid progenitor cells and CD34+ stem cells [10]. Therefore, it is logical to hypothesize that using an ACEi to block conversion from angiotensin I to angiotensin II would affect mitotic activity of progenitor stem cells, potentially inhibiting hematopoiesis.

The direct effects of angiotensin II also affect hematopoiesis [11-13]. The interaction between angiotensin II and AT1 receptor can lead to differentiation to the erythroid lineage, an effect that is blocked by losartan administration [1]. Losartan administration also blocks progenitor cell proliferation that is upregulated by angiotensin II [6], which supports the hypothesis that both angiotensin II and AT1 are involved in hematopoiesis, and that both ACE inhibitors and ARBs may inhibit this process. For this reason, our study includes patients who received either an ACEi or ARB.

In some cases, inhibition of the RAS may actually provide a protective effect against myelotoxicity by mediating a growth cycle arrest and preventing apoptosis during $\mathrm{S}$ phase of the cell cycle. Charrier et al. showed that mice treated with either ACEi (perindopril) or ARB (telmisartan) before and after irradiation demonstrated improved survival with faster hematopoietic recovery compared to controls [14]. This suggests that while RAS inhibitors may inhibit engraftment and hematopoiesis, they may also serve a protective role if used transiently during cytotoxic therapy. While difficult to extrapolate to the setting of autologous stem cell transplant, this data suggests opposing effects of hematopoiesis based on the timing of ACEi/ARB administration.

We chose to evaluate the potential clinical impact of ACEi and ARB on engraftment in a relatively homogenous group of patients with same underlying disease (multiple myeloma), receiving the same conditioning regimen (melphalan at $200 \mathrm{mg} / \mathrm{m}^{2}$ ). Our single institution retrospective study found no statistically significant difference in time to platelet or neutrophil engraftment, red cell transfusion requirement, length of hospital stay and time to neutropenic fever between patients who did or did not receive an ACEi or ARB. Our findings support 
that the use of low to moderate doses ACE inhibitor or $\mathrm{ARB}$ is safe to give in patients undergoing autologous SCT for multiple myeloma.

\section{REFERENCES}

[1] I. C. Haznedaroglu and M. A. Ozturk, "Towards the Understanding of the Local Hematopoietic Bone Marrow Renin-Angiotensin System," The International Journal of Biochemistry \& Cell Biology, Vol. 35, No. 6, 2003, pp. 867-880. doi.org/10.1016/S1357-2725(02)00278-9

[2] D. V. Vlahakos, et al., "Enalapril-Associated Anemia in Renal Transplant Recipients Treated for Hypertension," American Journal of Kidney Diseases, Vol. 17, No. 2, 1991, pp. 199-205.

[3] P. J. Conlon, et al., "Losartan in Post-Transplant Erythrocytosis," Nephrology Dialysis Transplantation, Vol. 11, No. 12, 1996, pp. 2524-2525. doi.org/10.1093/oxfordjournals.ndt.a027238

[4] C. Hubert, et al., "The Hematopoietic System: A New Niche for the Renin-Angiotensin System," Nature Clinical Practice. Cardiovascular Medicine, Vol. 3, No. 2, 2006, pp. 80-85. doi.org/10.1038/ncpcardio0449

[5] J. Walter, "Does Captopril Decrease the Effect of Human Recombinant Erythropoietin in Haemodialysis Patients?" Nephrology Dialysis Transplantation, Vol. 8, No. 12, 1993, p. 1428.

[6] K. E. Rodgers, et al., "Effect of Angiotensin II on Hematopoietic Progenitor Cell Proliferation," Stem Cells, Vol. 18, No. 4, 2000, pp. 287-294. doi.org/10.1634/stemcells.18-4-287

[7] M. Mrug, et al., "Angiotensin II Stimulates Proliferation of Normal Early Erythroid Progenitors," Journal of Clinical Investigation, Vol. 100, No. 9, 1997, pp. 2310-

\section{4. doi.org/10.1172/JCI119769}

[8] P. Van der Meer, et al., "Levels of Hematopoiesis Inhibitor N-Acetyl-Seryl-Aspartyl-Lysyl-Proline Partially Explain the Occurrence of Anemia in Heart Failure," Circulation, Vol. 112, No. 12, 2005, pp. 1743-1747. doi.org/10.1161/CIRCULATIONAHA.105.549121

[9] J. Cole, et al., "Lack of Angiotensin II-Facilitated Erythropoiesis Causes Anemia in Angiotensin-Converting Enzyme-Deficient Mice," Journal of Clinical Investigation, Vol. 106, No. 11, 2000, pp. 1391-1398. doi.org/10.1172/JCI10557

[10] S. Heringer-Walther, et al., "Angiotensin-(1-7) Stimulates Hematopoietic Progenitor Cells in Vitro and in Vivo," Haematologica, Vol. 94, No. 6, 2009, pp. 857-860. doi.org/10.3324/haematol.2008.000034

[11] F. Deshayes and C. Nahmias, "Angiotensin Receptors: A New Role in Cancer?" Trends in Endocrinology \& Metabolism, Vol. 16, No. 7, 2005, pp. 293-299. doi.org/10.1016/j.tem.2005.07.009

[12] V. J. Jokubaitis, et al., "Angiotensin-Converting Enzyme (CD143) Marks Hematopoietic Stem Cells in Human Embryonic, Fetal and Adult Hematopoietic Tissues," Blood, Vol. 111, No. 8, 2008, pp. 4055-4063. doi.org/10.1182/blood-2007-05-091710

[13] T. S. Park and E. T. Zambidis, "A Role for the ReninAngiotensin System in Hematopoiesis," Haematologica, Vol. 94, No. 6, 2009, pp. 745-747. doi.org/10.3324/haematol.2009.006965

[14] S. Charrier, et al., "Inhibition of Angiotensin I-Converting Enzyme Induces Radioprotection by Preserving Murine Hematopoietic Short-Term Reconstituting Cells," Blood, Vol. 104, No. 4, 2004, pp. 978-985. doi.org/10.1182/blood-2003-11-3828 